\title{
MASCULINIZAÇÃO DA HOMOSSEXUALIDADE MASCULINA NO GRINDR: DISCURSOS SOBRE MASCULINIDADE E DISCRIÇÃO
}

\author{
JÚLIA ANTÔNIA MAUÉS CORRÊA ${ }^{1}$ \\ MARCOS DA SILVA CRUZ ${ }^{2}$
}

\author{
Curso de Licenciatura em Letras - Língua Portuguesa \\ Instituto Federal de Educação, Ciência e Tecnologia do Pará - campus Belém \\ Av. Alm. Barroso, 1155 - 66093-020, Belém - Pará - Brasil \\ Programa de Pós-Graduação em Letras \\ Universidade Federal do Pará \\ Rua Augusto Corrêa, 01 - 66075110 - Belém - PA - Brasil \\ juliamaues@gmail.com, marcozcrus.ifpa@gmail.com
}

\begin{abstract}
Resumo. Esta pesquisa propõe pensar os modos de identificação de sujeitos homossexuais masculinos, sobretudo aqueles que defendem a ideia de masculinização da masculinidade homossexual e a discrição da feminilidade. Esses usuários adquiriram latência nos aplicativos de relacionamento, onde promulgam determinações sobre os corpos dos parceiros-em-potencial, embora vivenciem as ambiguidades de cálculo das diferenças identitárias. Investigamos os usuários do aplicativo gay Grindr, narrando a história de dois deles. Como resultados, constatamos que o corpo funciona como a escritura pela qual são inscritos uma série de pares opositivos e funciona como prova do exercício performativo debilitado de masculinização e a projeção da masculinização no parceiro-em-potencial como um suplemento performativo.
\end{abstract}

Palavras-chave: discurso; homossexualidade masculina; masculinização; debilidade performativa; Grindr.

\begin{abstract}
This paper aims to think about the modes of identification of male homossexual subjects, mainly those who defends the idea of masculinization of homossexual masculinity and discretion of feminility. These users acquired latency in relationship apps, which enact determinations about the potencialpartners bodies, although experience the ambiguities of identity differences calculation. Investigate the users of gay app Grindr, relating the narratives of two of them. As results, found that the body works as a deed by which are subscribed a series of oppositional pairs and works as a proof of masculinity
\end{abstract}

\footnotetext{
${ }^{1}$ Doutora em Linguística Aplicada pela Universidade Estadual de Campinas (Unicamp) e professora titular do curso de Letras - Língua Portuguesa do Instituto Federal de Educação, Ciência e Tecnologia do Pará, campus Belém.

${ }^{2}$ Mestrando no Programa de Pós-Graduação em Letras da Universidade Federal do Pará (UFPA). Possui graduação em Letras - Língua Portuguesa pelo Instituto Federal de Educação, Ciência e Tecnologia do Pará e é graduando no curso de Pedagogia pela mesma instituição.
} 
impaired performance exercise and a projection of masculinization in the potencial-partners as a performative supplement.

Keywords: discourse; male homosexuality; masculinization; impaired performance; Grindr.

\section{INTRODUÇÃO}

A pós-modernidade marcou o descortinamento de um cenário antagônico entre as compreensões sobre identidade e, sobretudo, acerca da homossexualidade. Começamos a contatar que, de um lado, há uma forma de pensamento heterocentrada (PRECIADO, 2014), voltada ao controle e naturalização da (heteros)sexualidade, e, por outro lado, os sujeitos considerados dissidentes que irrompem as fronteiras impostas. Contudo, a forma de racionalidade heterocentrada infiltrou-se nas práticas sociais e nos esquemas cognitivos dos sujeitos homossexuais, masculinos sobretudo, a partir da noção de masculinidade, consolidando uma divisão identitária interna ao grupo LGBT $^{3}$ (CRUZ, 2020). Assim, tem-se hoje duas populações: os "machões e discretos", que condenam a feminilidade e defendem uma concepção restritiva de masculinidade, próxima da heterossexualidade, e, o grupo antagônico de sujeitos que desvirtuam das normas de uma heterossexualidade aparente em práticas sociais públicas.

Assim como a heterossexualidade interpretou a homossexualidade pela noção de sujeito do iluminismo, imutável a partir desde o nascimento e predestinado a cumprir uma linearidade de gênero (BUTLER, 2003), há a reificação do critério para percepção dos "machões e discretos" como sujeitos imutáveis, categorizáveis tão somente pelo discurso de condenação da feminilidade e de exacerbação de uma heterossexualidade aparente. Todavia, ao reconhecermos que a pós-modernidade também descortinou a noção de sujeito fragmentado, questionamos como os "machões e discretos" no Grindr constroem suas identidades discursivas.

Como introito elucidativo, convém sinalizar que o Grindr foi selecionado por apresentar-se como o aplicativo que, com o passar dos anos, especializou-se em relações de sujeitos homossexuais masculinos e onde os discursos de masculinização encontramse com maior frequência e latência. Outro esclarecimento, que permeia o artigo, são os conceitos de masculinidade e masculinização: entendemos a masculinidade como uma configuração social e cultural que estabiliza, à sua época, uma noção de homem, podendo ser manifesta de diferentes formas. Em caminho contrário, a masculinização apresenta-se como um processo de estreitamento das possibilidades de masculinidade, forjando a ideia de que apenas uma masculinidade, a heterossexual, seria tolerável nos sujeitos sociais.

\footnotetext{
${ }^{3}$ LGBT é a sigla para Lésbicas, Gays, Bissexuais e Travestis/transsexuais. Reconhecemos a atualização terminológica da sigla para LGBTQIA+ nos últimos anos, contudo utilizamos o recurso êmico anterior em decorrência da natureza do objeto analisado e da ausência de aplicativos projetados para as outras letras do grupo. Como já indicado em Corrêa e Cruz (2019), é inerente aos aplicativos de relacionamento, como reflexo de uma política de identidade, a natureza de autoespecialização para uma população específica. Contudo, é ainda latente a necessidade de pensar as políticas identitárias para queers, intergênero, assexuais e quais outros sujeitos que não visibilizados nas midialidades.
} 
No projeto de descrevermos as construções discursivas das identidades dos "machões e discretos", elucidamos, na primeira parte, o processo de efeitos de sentido sobre homossexualidade pelos quais houve a promoção do deslocamento dimensional dos sujeitos para os aplicativos de relacionamento, enfatizando o papel do corpo como materialidade discursiva; na segunda parte, analisamos as narrativas de dois usuários do Grindr sobre o papel da feminilidade, da masculinidade e da discrição, bem como seus condicionantes, na estabilização de uma identidade homossexual masculinizada. Por último, pontuamos algumas considerações sobre o processo de constituição da identidade homossexual masculina, observando os sentidos sobre a relação entre papéis sexuais, identidade de gênero, debilidade performativa de masculinização e a projeção em um parceiro-em-potencial.

\section{A HOMOSSEXUALIDADE MASCULINA, A CONSTRUÇÃO DA ABJEÇÃO E O DESLOCAMENTO DIMENSIONAL}

A máxima "que seja, mas não perto de mim" sintetiza a especificidade que permeia o processo de constituição das identidades homossexuais. $\mathrm{O}$ desenvolvimento das práticas identificatórias é atravessado, historicamente, por diferentes instâncias, instituições, discursos e agentes que reverberam uma concepção ideológica condenatória sobre identidades dissidentes à heterossexualidade e à cisgenericidade, de um lado. Em situações cotidianas, registram-se enunciados do tipo "podem ser gays, mas não precisam escancarar na rua", ou ainda os debates sobre a demonstração de afeto entre casais gays e heterossexuais em vias públicas. Isto é, as relações sociais demonstram que vivenciamos uma sociedade parcialmente tolerante a depender da "globalização de mercado" (TREVISAN, 2018, p. 17), a qual reconhece a existência dos corpos dissidentes desde que estes não concorram com os pressupostos de espaços sociais construídos sob a égide da heterossexualidade.

O sustentáculo desta compreensão de mundo descortina uma noção fortuita tanto aos estudos sobre identidade como aos estudos sobre discurso: as concepções de sujeito. Hall (2006) fornece uma interpretação pautada nos pressupostos iluministas, nas elucubrações sociológicas e na insurgência e emergência dos estudos culturais. Ao descrever cada momento, depreende-se a aproximação das duas primeiras tendências ao compartilharem o entendimento sobre a imutabilidade da identidade do sujeito social a partir do aspecto biológico, o que ocasiona o pensamento comum de invariabilidade das identidades de gênero e sexuais a partir da declaração "é menino" ou "é menina", como nos lembra Butler (2003) e Livia e Hall ([1997] 2010). Logo, desde os primórdios sociais, sujeito era aquele que se mantinha reiterando as mesmas características identitárias durante toda a vida.

Por outro lado, com a emergência dos estudos culturais na pós-modernidade, o entendimento sobre a constituição do sujeito passou por revisões. De concepções muito restritas, passamos de uma explicação de causalidade particular para uma postura arqueológica (FOUCAULT, 1988). Assim, começamos a encarar o sujeito social como efeito de diferentes "paisagens culturais de classe, gênero, sexualidade, etnia, raça e nacionalidade" (HALL, 2006, p. 9), permitindo, no campo das relações de gênero e sexualidade, observar o funcionamento de aparatos discursivos pelos quais são constituídas as diferenças entre os corpos aceitos e aqueles colocados à abjeção. 
Dentre os aparatos, Bourdieu (2012), ao analisar a constituição da noção de masculinidade e de opressão/dominação masculina, constata a existência de um sistema de causalidade circular. Este é sustentado pela articulação dos critérios de sexo, de gênero e de sexualidade, os quais são construídos como argumentos naturais, de origem divina sobretudo, a fim de delimitar os papéis sociais, instaurando um quadro de pares opositivos (masculino/feminino; heterossexual/homossexual; cisgênero/transgênero). Os jogos de sentido entre as formas de identificação destacavam o segundo elemento sempre de maneira pejorativa, não permitida, o que ainda hoje funciona como lógica de pensamento nas relações homoeróticas masculinas.

Nas práticas cotidianas, o sistema de causalidade funciona como instrumento de delimitação dos espaços sociais e de possibilidade de mobilidade entre diferentes práticas sociais. Louro (2001) identifica o momento de anexação entre regência dos pressupostos religiosos e a institucionalização da sexualidade como marco histórico de construção das noções de normalidade e de abjeção: até o século XIX, a postura da igreja consistia na condenação das relações homoeróticas ao visualizá-las como sodomia e como desvio de caráter; a partir da década de 70, a homossexualidade foi institucionalizada, tornando-se objeto dos discursos jurídicos e médicos, os quais a concebiam como patologia psíquica e/ou desvio de caráter. É importante observar que, além da preservação de um tipo de "gênese religiosa", a sexualidade nunca deixou de ser ponto de referência na organização social, exercendo papel preponderante na formatação de espaços para os corpos dissidentes, seja nos hospitais, nos manicômios ou nas prisões.

Como exemplos de formatação, Sedwick (2007) descreve Stonewall (inn) como um espaço geograficamente delimitado para a realização de práticas homossexuais, um bar, com poucos elementos identificatórios e, sobretudo, um espaço para as pessoas expressarem-se de modo menos preocupado com as imposições previstas do outro lado da porta. Em solo brasileiro, Perlongher (1987) descreve as políticas de masculinidade dos michês em São Paulo, pontuando cinemas, saunas, praças escuras e os banheiros como espaços de exercício de práticas conhecidas pela sociedade em geral, mas não toleradas à luz do sol. Em ambos os casos, a sociedade reiterava a máxima "que seja, mas não perto de mim", conjugando a existência de homossexuais à distância de quaisquer práticas sociais públicas.

Embora aparentemente cotidiana, a movimentação de pessoas nesses espaços adensou-se, o que implicou a instalação de políticas repressivas intensas. Tanto nos Estados Unidos como no Brasil, os locais frequentados pelos sujeitos dissidentes sofreram diversas investidas policiais e foram taxados como espaços ausentes de profilaxia ${ }^{4}$. Assim sendo, no caso brasileiro, pontos específicos de encontros amorosos/sexuais foram paulatinamente abandonados pelo receio dos frequentadores de serem, institucionalmente, condenados por práticas de "perversão", "adultério", "prostituição" etc. Portanto, os encontros entre homens tornaram-se marcados pelo medo da repressão

\footnotetext{
${ }^{4}$ Miskolci (2017), ao descrever o papel da aids (em letra minúscula), constata que a construção de sentidos sobre o vírus foi promovida muito mais por conta dos sujeitos aos quais a ideologia (médica, jurídica, religiosa e popular) convencionou associar, do que ao funcionamento de políticas de prevenção viral geral, como o sarampo ou a hepatite. Logo, dissimulou-se uma relação restrita entre homossexualidade e aids, abrangendo os sujeitos, as práticas e os espaços de interação pelos quais os homossexuais circulavam, prova disso está nos dados da pesquisa de Soares (2011) que presenciam a consolidação da ideologia religiosa sobre a aids e as práticas sexuais entre pessoas do mesmo sexo/gênero.
} 
física e simbólica, e a promoção da necessidade de ratificação da masculinidade mediante sua matriz heterocisgênero.

Como efeito das políticas de higienização, do desenvolvimento da web 2.0 e do receio interacional, os homossexuais masculinos deslocam-se para os aplicativos de relacionamento. Miskolci (2017) descreve o surgimento de diferentes aplicativos voltados ao público LGBT, dentre os quais, no caso do público masculino, destaca-se o Grindr ${ }^{5}$. Embora pressuponha-se que os aplicativos seriam um local de exercício anti-hegemônico das identificações, houve a retomada dos pares opositivos sobre a noção de sujeito, sobretudo "[pel]a infiltração dos valores da heterossexualidade compulsória (...) caracterizados pela condenação da feminilidade e a defesa da discrição das relações homoeróticas (...) em troca de acessibilidades e cidadania" (CORRÊA e CRUZ, 2019, p. 114).

A infiltração dos valores e do exercício de uma heterossexualidade aparente são sustentados, como apontou por Bourdieu (2012), pelo sistema de causalidade circular. Este, mais especificamente, engendra a masculinidade como nobreza ao deflagrar valores sociais distintos para práticas ligadas ao feminino, isto é, feminilidade e passividade são conceitos que inferiorizariam o valor social do corpo e do desejo amoroso/sexual nas interações estabelecidas no Grindr. Em consonância, a sintaxe relacional estabelecida é pautada na exacerbação de uma masculinidade heterossexual e da coibição da feminilidade como traço subjetivo. Contudo, como lembra Hall (2006), a identidade dos "machões e discretos" também é atravessada por "diferentes paisagens", as quais devem ser compreendidas a fim de elucidar as bases funcionais das polarizações acerca dos papéis de gênero e de sexualidade.

\section{O CORPO COMO MATERIALIDADE DISCURSIVA: OBSERVAR AS IDENTIDADES HOMOSSEXUAIS MASCULINAS}

Observar o corpo como materialidade discursiva realizar-se-á na medida em que, ao pontuar os aspectos históricos acerca da construção abjeta da homossexualidade masculina (cf. seção 1), percebemos que os sentidos, historicamente localizados, atravessam os corpos dos sujeitos sociais, delimitando formas de agir, vestir, falar etc., endereçando-os ao cumprimento ou não das investidas do discurso sobre a masculinização. Nesse viés, recorremos à teoria proposta por Fairclough e Chouliaraki (1999) e Fairclough $(2001 ; 2012 ; 2020)$ para analisarmos o discurso como componente social que constrói e desconstrói desigualdades, neste caso as construções identitárias de homossexuais masculinos mediante a heterossexualidade-aparente compulsória.

A partir de uma citação de Foucault, Fairclough (2001) propõe uma Análise Crítica do Discurso (i.e. ACD) que compreende a noção de discurso como "desempenhos verbais", formas sócio-históricas de delimitação do uso de enunciados, bem como a constituição de sentidos sobre sujeitos, objetos e conceitos. Neste caso, os sujeitos são

\footnotetext{
${ }^{5}$ Corrêa e Cruz (2019, p. 113) advertem que "embora o Grindr tenha sido, em sua fase inicial, projetado para quaisquer sujeitos homoeróticos, a configuração social, marcada pela 'política de identidade' (MIGNOLO, 2008) interna ao grupo LGBTQ, acabou por segmentar os usos de determinados aplicativos". Logo, por ocasião dos usos e das divisões políticas (que não são objeto de discussão neste momento), o Grindr tornou-se um aplicativo restrito ao público homossexual masculino.
} 
homoeróticos masculinos, marcados pelas diferenças sociais como apontou Hall (2006), constituindo-os a partir de diferentes papéis exercidos nas práticas sociais. A natureza discursiva de sujeito, para Fairclough (2001, p. 69), reside no reconhecimento de certa

preferência a postulação de um 'sujeito da medicina' unitário, que daria coerência a essas várias modalidades enunciativas e posições de sujeito, Foucault sugere que essas várias modalidades e posições manifestam a dispersão ou fragmentação do sujeito.

Como descrito na seção 1, até o surgimento da visão arqueológica foucaultiana, a compreensão de sujeito restringia-se à visão unitária, monovalente, de invariância no tempo e no espaço sociais. Até então a noção de discurso está atrelada somente ao nível pré-discursivo, ao já existente passível de resgate indiscriminado. Em caminho diferente, a perspectiva foucaultiana viabilizava a compreensão do discurso como um já-dito e um já-autoral, que, no momento de uso, se auto-inscreve na enunciação e inscreve a posição do sujeito. Portanto, o discurso é simultaneamente a estabilização de sentido, por um lado, a renovação de sentido, por outro, permitindo a localização de determinadas identidades na sociedade.

Embora os pontos de concordância com Foucault, Fairclough (2001) advoga a ampliação do foco de observação, deslocando-o para uma visão social discursivamente orientada. Para o linguista britânico, a análise do discurso precisa ser localizada em um tipo de posição intersticial, funcionando como uma modalidade de ciência social, a fim de observar o papel da linguagem nas interações, relações e conflitos sociais. Assim sendo, o autor caracteriza a Análise Crítica do Discurso como um "método em pesquisa social" (FAIRCLOUGH, 2012, p. 307), o que acarreta pensá-la a partir das demandas sociais, as quais, nesta pesquisa, relacionam-se com o exercício da masculinidade e da masculinização na constituição da identidade homossexual masculina no Grindr.

Reconhecemos que Fairclough $(2001 ; 2012 ; 2020)$ não se dedica ao estudo da performatividade de gênero e o corpo como materialidades discursivas, mas também acreditamos que nosso procedimento representa uma extensão, senão uma atualização, na corrente teórica supracitada. Em primeiro lugar, a observação do corpo como materialidade discursiva nos fornece a deflagração dos modos pelos quais os discursos sobre identidade atravessam a vida dos sujeitos em práticas situadas. Em segundo lugar, permite-nos apreender quais dimensões e instrumentos o corpo mobiliza para reificar ou subverter os sentidos acerca da masculinidade homossexual. Em ambos os aspectos, a notação de Fairclough sobre o discurso ser um tipo de ação social está presente, da voz (invisível) de outrem que (des)autoriza as formas de ser e viver em sociedade.

Segundo o disposto pela ACD, o discurso, enquanto dimensão social, é manejado por diferentes sujeitos sociais para a delimitação de espaços e papéis. Esse exercício se dá em três dimensões, as quais funcionam em um regime de reciprocidade, a saber: a prática social, como o conjunto de atividades sociais exercidas pelos sujeitos; a prática discursiva, situação de comunicação pela qual os sujeito atualizam (reificando ou subvertendo) o papel social que ocupam; e o nível textual, materialidade que permite a postura analítica ao fornecer dados de análise, o que, nesta ocasião, inclui o corpo como escritura do tempo e do espaço social, histórico e cultural. A partir da tabela 1, é possível arrolar os critérios dispostos para cada dimensão da análise tridimensional. 
Tabela 1 - Dimensões da análise tridimensional

\begin{tabular}{|ccc|}
\hline Nível Textual & Prática Discursiva & Prática Social \\
\hline Vocabulário & Produção & Ideologia \\
Gramática & Distribuição & Sentidos \\
Coesão & Consumo & Pressuposições \\
Estrutura & Força & Metáforas \\
& Coerência & Hegemonia \\
& Intertextualidade & Orientações econômicas, \\
& & políticas, culturais e \\
& & ideológicas. \\
\hline
\end{tabular}

Adaptado de Chouliarack e Fairclough (1999) e Fairclough (2001).

Em síntese, defendemos a investigação do corpo como materialidade discursiva. Ao contatar as investidas históricas sobre os gestos, comportamentos linguísticos, vestimentas, brinquedos, entre outros instrumentos, somos confrontados, a longo prazo, com a perfilação de corpos como tolerados (por seguirem a norma de heterossexualidade aparente) ou como abjetos, deslocando-se dimensionalmente a fim de realizarem suas práticas identitárias, sexuais e/ou amorosas. É sobre os sentidos que atravessam esse deslocamento, sua configuração e como são articulados com as diferentes paisagens culturais que buscamos entender a identidade dos "machões e discretos".

\section{DUAS NARRATIVAS PERFORMATIVAS DE USUÁRIOS DO GRINDR}

Antes de incorrermos sobre os resultados, gostaríamos de sintetizar o percurso de entrada, seleção e análise dos dados. Sobre o primeiro, criamos um perfil no aplicativo, identificando o propósito de sua residência durante os meses de agosto a dezembro de 2019. Para a seleção, elaboramos três critérios: (i) apenas os perfis que, simultaneamente, apresentaram textos nos espaços de descrição pessoais e nas categorias de enquadramento $^{6}$; (ii) os usuários que, na área de descrição pessoal, utilizaram termos semelhantes, análogos ou antagônicos sobre masculinidade e discrição; (iii) os perfis localizados até um metro de distância do ponto de referência ${ }^{7}$. Para a análise, optamos

\footnotetext{
${ }^{6}$ Os perfis do Grindr podem ser divididos em duas partes: a primeira é composta por um espaço no qual o usuário tem a possibilidade de descrever-se com suas próprias palavras; em seguida, como segunda parte, há um tipo de tabela pela qual o usuário pode sinalizar as características corporais (peso, altura etc.), situação de relacionamento (solteiro, em relacionamento aberto, entre outros), o objetivo no aplicativo e a realização de exame de HIV.

${ }^{7}$ Delimitamos como ponto offline a Delegacia do bairro da Cabanagem, periferia de Belém. Este gesto foi gerado por percebermos que a dinâmica de funcionamento do aplicativo pela geolocalização mudaria as diferenças identitárias dos participantes, bem como por hipotetizarmos que o processo de constituição dos bairros belenenses (mas não somente) incidem sobre as compreensões da identidade homossexual
} 
pela interpretação das categorias de identificação pessoal e uma entrevista semiestruturada $^{8}$ por meio do bate-papo do aplicativo.

Mediante as elucidações metodológicas passamos à análise. Esta visa narrar a vida social (MOITA LOPES, 2006) dos usuários do aplicativo, o que demandou a enumeração das dimensões mais expressivas (mas não as únicas) do discurso sobre masculinidade e discrição. Assim, a partir da análise tridimensional (FAIRCLOUGH, 2001), delimitamos cinco máximas que atravessam a constituição da identidades homossexuais masculinas de "Tired" e "Pantera Negra" e que são materializadas por meio do corpo, a saber: (i) ser passivo é ser afeminado; (ii) a comunidade do bairro e do trabalho como pilares de propagação da masculinização; (iii) a relação dialética entre on-line e off-line; (iv) a masculinização como tripla aparência; (v) e a ideia de machão como efeito de um "abismo identitário".

Embebido em um contexto de receio de exposição das relações homossexuais em público, "Tired!" apresenta como condição de interação o apagamento de qualquer traço que deponha em direção ao questionamento de sua masculinidade, tendo como principal elemento corruptor seu reverso, a feminilidade. Para o usuário, os elementos corporais e de corporalidade conduziriam à ridicularização da identidade masculina e sobretudo adensam as dificuldades de convivência em espaços públicos, regidos por valores heterossexuais. A materialidade discursiva sobre a feminilidade evidencia-se nos níveis vocabular e gramatical da fala de "Tired!" com o uso de expressões como "ridicularizado", "poses das fotos", funcionando, respectivamente, para designar o modus vivendi de homens publicamente gays e um dos critérios de verificação da feminilidade de um usuário.

Ainda sobre o nível gramatical, o usuário reconhece a dificuldade de reiteração das performances de masculinização, utilizando como recurso a tática de evitar gestos e expressões faciais. Assim, "Tired!" acompanha suas "caras e bocas" a fim de distanciarse da possibilidade de julgamento sobre a sua identidade sexual, acarretando retaliações simbólicas nas práticas sociais cotidianas. As "caras e bocas" são elementos constituintes, segundo o usuário, de uma gama de referências à feminilidade, argumentando que "Tudo o que chama [atenção] causa constrangimento, dependendo da situação". O termo "tudo" indexicaliza para quaisquer formas de feminilidade e as insere no invólucro do constrangimento como efeito sensorial da reprovação sobre a evidência pública da homossexualidade (efeminada).

O uso de "dependendo da situação" pode ser interpretado, no conjunto do enunciado, como a relativização e a circunscrição dos espaços possíveis de manifestação da feminilidade. A partir da sinalização sobre a discrição, seja no usuário ou no parceiroem-potencial, a feminilidade é relativizada entre os espaços públicos e privados, cabendo a este a função de permissividade de exposição de performances não toleradas em espaços públicos, resguardando-o de retaliações. Logo, para "Tired!", a discrição é um item

masculina. Portanto, adotar o critério de divisão administrativa significa perceber que os sentidos oscilam a partir de diferenças de classe social, idade, raça, poder aquisitivo, entre outros.

${ }^{8}$ A entrevista foi baseada no modelo de Santos Filho (2015), visando recolher respostas dos usuários para as seguintes questões: você se enquadra como masculino ou efeminado? O que torna você masculino ou efeminado? Você é uma pessoa discreta? Quais atitudes (não) o enquadram nesse perfil? 
imprescindível na sintaxe relacional como forma de regulação da feminilidade, bem como a masculinização como forma de dissimulação da heterossexualidade.

O fundamento ideológico sobre o qual se assenta a percepção de "Tired!", e inscrito no nível coesivo, revela que os homossexuais "devem agir como um homem que somos, afinal nossas preferências só dizem respeito a nós mesmo" (sic.). O posicionamento destaca uma concepção de homem atrelada a um quadro unidirecional, o qual prevê identidades amorfas, unificadas, baseadas na denominação de gênero pelo sexo biológico ${ }^{9}$. O efeito concretiza-se a partir do momento em que a subjetividade do homossexual masculino é podada pela lente ostensiva da heterossexualidade aparente, corroborando para a naturalização de categorias binárias e reificação de condições abjetas àqueles que destoam do paradigma.

Na mesma direção sobre a importância de discrição da feminilidade, "Pantera Negra" a compreende não como "um ponto a menos [, mas] o ponto principal". O usuário acredita que a discrição está ligada intimamente à feminilidade, tendo sua razão de existência em decorrência dos efeitos que a feminilidade pode acarretar. Essa suplementariedade, e sobretudo a condenação da feminilidade, é sublinhada pelo usuário quando afirma que "[é] tanta frescura que tô [i.e. estou] quase crendo que isso é um aplicativo cheio de mulheres disfarçadas" 10 , depondo que, ao comparar homossexuais masculinos com mulheres, o usuário recupera sentidos pejorativos acerca dos elementos indexicalizadores da feminilidade e aproxima-se de um gesto de expurgo de identidade masculina feminilizada/efeminada.

Ao autodescrever-se, "Pantera Negra" destaca aspectos considerados positivos para a identidade masculinizada, de aproximação da ideia de heterossexualidade. A partir das categorias de enquadramento, ser "torneado", composto por peso e altura ideal (no caso do usuário, cerca de um metro e setenta de altura e oitenta quilos) inscreve o cumprimento dos requisitos imagéticos-corporais de masculinidade masculinizada. Em conjunto, o indicativo corporal-comportamental "elegante" depõe sobre as formas de vestimenta específicas e de comportamentos em espaços públicos, inflando a imagem de heterossexualidade aparente e garantindo o trânsito e a permanência em diferentes práticas sociais.

Embora os aspectos corporais e comportamentais, o que adquire imprescindibilidade é o exercício dos papéis sexuais no momento da felação. Para "Pantera Negra", a versatilidade sexual, ao remeter a possibilidade de penetrar e/ou ser penetrado, insere-o em um paradigma intersticial, entre a passividade-feminilidade e a atividade-masculinidade. Ou seja, ocupar o papel de passivo demandaria, na compreensão do usuário, a manifestação, por extensão, de traços de feminilidade, infringindo os limites

\footnotetext{
${ }^{9}$ A interpretação do enunciado, obviamente, não finda nessa apreensão. Cruz (2019) e Côrrea e Cruz (2019) apontam também que, se observado pela ótica de Van Dijk (2008), o excerto "só dizem respeito a nós mesmo" ilustra o processo de diluição da ideologia no discurso, fazendo o informante compreender identidade e desejo sexuais como efeitos de escolhas particulares, quando, na verdade, são sentidos delimitados historicamente. Para efeito de análise, a interpretação exposta no escopo do texto é suficiente para conduzir-nos, neste momento, às respostas do questionamento inicial proposto.

${ }^{10} \mathrm{O}$ trecho também instiga sobre o processo de compartimentação identitária dos aplicativos, voltados, especificamente, a cada parcela da sigla LGBT. Cruz (2019), em uma parte de sua pesquisa, observa essa constituição de departamentos, de núcleos, como resultado das "políticas identitárias", de separação dos grupos a partir de interesses próprios e espaços específicos de interação.
} 
performativos de identidade na publicidade. Por outro lado, atuar como ativo garantiria um tipo de pré-disposição ao exercício de elementos corporais e da corporeidade masculinos heterossexuais.

Ao serem indagados sobre as práticas sociais nas quais vivenciam de forma acirrada a negociação dos traços performativos de identidade sexual, os usuários pontuaram que transcendem a prática social/discursiva digital do Grindr. "Tired!" relata que a recepção de homossexuais no bairro onde mora ${ }^{11}$ é marcada pela discriminação, fazendo-o desabafar "infelizmente, discriminação". O uso do advérbio inscreve, de maneira subjetiva, a experiência do usuário como atravessada por restrições das relações homossexuais a ambientes privados e marcada pela postura condenatória e de retaliação por parte dos vizinhos. O efeito é a necessidade de requisição de performances identitárias cerradas em torno da heterossexualidade aparente nas apresentações e interações no aplicativo.

De igual modo, "Pantera Negra", ao ser questionado sobre o tipo de convivência estabelecida com os pares no bairro, informa que "não convivo e nem falo com a vizinhança, moro em condomínio fechado e em apto [apartamento]". O núcleo da informação reside também no distanciamento, ou melhor, da ausência de interação com os congêneres do bairro onde habita, o que permite especular que, assim como em "Tired!", a relação é marcada pela cultura da discriminação e pelo receio de retaliação física ou simbólica como efeito. Em um jogo de ausência de interações, Reis (2015) descreve que as chances de entender a pluralidade identitária e saber como manejá-la é penosa, fazendo com que os homossexuais masculinos, em primeiro lugar, não percebam os instrumentos culturais de silenciamento e, em segundo, reverberem a masculinização como única forma de vida.

Os discursos de masculinização materializam-se na fala dos dois usuários de forma semelhante. De modo geral, a prática discursiva é marcada, no nível de produção, pelo "sufocamento" histórico em torno da masculinidade heterossexual e do regime de troca de acessibilidades sociais, incitando os usuários a condenarem performances femininas e enfatizando traços corporais e de corporeidade próximos da heterossexualidade aparente. Os sentidos são, no nível de distribuição, dependentes dos diferentes espaços geográficos pelos quais os usuários circulam e a quantidade de perfis na região abrangida pelo sistema de geolocalização do aplicativo. Como condição de recepção, os parceiros-em-potencial devem apreender os requisitos identitários, verificar se preenchem a imagem projetada pelos "machões e discretos", para, em seguida, estabelecer algum tipo de contato.

Apesar de não ser o foco da pesquisa, a relação entre as construções identitárias online e offline apresentaram-se como uma dimensão de força vital para a estabilização dos efeitos de sentido sobre a masculinização da homossexualidade masculina no Grindr. Longe de uma estabilização necessária somente ao parceiro-em-potencial, questionamos como os "machões e discretos", aqueles que defendem a masculinização, vivenciam o

\footnotetext{
${ }^{11} \mathrm{O}$ bairro da Cabanagem, periferia da cidade de Belém, é caracterizado por momentos pontuais de latência das identidades homossexuais, principalmente em festas comemorativas como São João. Na ocasião, os gays efeminados são permitidos, com maior tolerância, se vestirem de mulheres e dançar com passos marcadamente femininos as danças típicas. Todavia, é preciso observar que, na maioria dos casos, essa permissividade da feminilidade serve como amparo para a ênfase da necessidade de masculinização.
} 
regime impositivo, como lidam com as paisagens identitárias, para a localização dentro de um sistema social que é, ao mesmo tempo, o repetido (sobre a homossexualidade) e o inédito (as relações mediadas pela internet e as imagens de si construídas online). Nesse caminho, constatamos que a identidade dos "machões e discretos" é menos marcada pela regularidade do que pela instabilidade de um exercício dissimulado constante, perfilado por momentos de deslize.

Ao considerar a condenação da feminilidade e da pontuação de traços performáticos de masculinização, questionamos os usuários sobre as estratégias mobilizadas para evitar a incorrência da feminilidade em relações públicas. Além da pontuação sobre a ausência de realização de "caras e bocas", de uso de expressões linguísticas, do tônus muscular e do comportamento reservado, observamos que "Tired!" e "Pantera Negra" reconhecem a fragilidade performativa de masculinização: o primeiro afirma "tento né" para caracterizar o processo de manutenção da heterossexualidade aparente, enquanto o segundo não pontua fragilidade alguma no exercício da masculinização.

Em decorrência de fundamentos distintos, analisaremos, em primeiro lugar, o que o caso de "Tired!" permite-nos compreender. Para o usuário, a feminilidade não é uma especificidade do parceiro-em-potencial, mas uma singularidade incrustada em sua identidade, a qual precisa ser regulada constantemente. Todavia, como a regulação não é um processo de aproveitamento total, o acompanhamento dos traços identitários de feminilidade falham em determinados momentos, fazendo-o ingressar em um jogo de tentativas de regulação por conta do risco de retaliações. Mais do que isso, o usuário insere-se em sistema gradual, de articulação das diferenças identitárias, o qual visa o êxito parcial. Logo, a lacuna deixada pelo exercício performático debilitado demanda outra unidade ou entidade que realize tal função: o parceiro-em-potencial.

No caso de "Pantera Negra", o argumento resume-se em "falo normal, me trajo como gosto e meu gosto condiz com o que a sociedade considera politicamente correto". Embora aparente uma certa conscientização sobre o funcionamento dos dispositivos de controle da sexualidade, o discurso do usuário, ao ser equacionado com as informações sobre a versatilidade e a relação de suplementariedade entre discrição-feminilidade, cogita-se outro cenário, não-dito, para o usuário: quando "Pantera Negra" diz que é preciso combater a feminilidade por meio da discrição e reconhece que esta está parcialmente presente em suas performances identitárias por conta da versatilidade sexual, podemos hipotetizar que os traços elencados são uma parte do projeto de masculinização, marcado também por elementos não quistos, que conduzem à debilidade e ao parceiro-em-potencial.

Pelo questionamento do exercício da masculinização em si, ao invés de somente discutirmos as regularidades e a efetivação dos pressupostos de uma heterossexualidade aparente, verifica-se a debilidade performativa de controle da feminilidade. Esta, motivada pela demanda dos papéis sexuais ou pela identificação, é uma dimensão que não pode ser anulada da identidade homossexual, somente introjetada a espaços privados em momentos difusos. Por conta disso, os usuários precisam de outras entidades que auxiliem na manutenção das identidades masculinizadas, cabendo, neste caso, aos parceiros-em-potencial, e atravessando as práticas discursivas do Grindr. 


\section{A PORTA ENTREABERTA DO ARMÁRIO}

A identidade homossexual masculina localiza-se em processo histórico de crescentes e decrescentes sobre os sentidos acerca da identidade e das práticas entre pessoas do mesmo sexo/gênero. A tolerância é a dimensão intrínseca às possibilidades de subjetividade dos sujeitos, ligada ao cumprimento de performances identitárias que dissimulem a heterossexualidade, evocando a ideia de sujeito unitário em sexo, gênero e sexualidade nas práticas públicas. Contudo, esse critério apresenta-se instável nas diferentes conjunturas históricas e no funcionamento temporal, pois, quando desestabilizado, comprime os sujeitos antes tolerados à margem, ausentes de condições básicas de reconhecimento como sujeito de direito e cidadãos.

No âmbito simbólico e material, verificou-se o deslocamento dimensional dos homossexuais (masculinos) para os aplicativos de relacionamento, neste caso o Grindr. Esse procedimento, embora aparente digressivo em sua totalidade, é atravessado pela manutenção dos valores de masculinização da homossexualidade masculina, incutindo-a como ideologia sobre a "única" possibilidade de vivenciar as relações homossexuais e manter as acessibilidades sociais na publicidade. Logo, o discurso (re)inscrito nos perfis dos "machões e discretos" prevê a anulação da feminilidade como traço performativo destoante de uma heterossexualidade aparente e por representar uma abertura indesejada para o questionamento da identidade de gênero do sujeito.

A ideologia de masculinização da homossexualidade masculina incide diretamente sobre os corpos dos sujeitos, tornando-os escrituras históricas sobre os valores culturais de uma sociedade. O corpo torna-se uma prova das formas de sociabilidade dos sujeitos homossexuais masculinos, perfilada por diferentes instrumentos, dispositivos, instâncias e valores estéticos, prevendo a modulação dos modos de vestir, de falar, de gesticular e da composição anatômica. O reconhecimento e cumprimento dessas demandas garante mínimas condições de circulação em diferentes práticas sociais, bem como seu avesso justificaria a postura de afastamento forçado e forçoso da pluralidade de papéis e das práticas sociais.

Por sua natureza de esquecimento, a ideologia de masculinização apresenta seus efeitos e demandas aos usuários, mas nunca aponta seus fundamentos e instrumentos. Os usuários reconhecem a imperatividade da condenação da feminilidade e da defesa dos traços da heterossexualidade aparente, definindo, na maioria dos casos, como uma questão de gosto ou de preferência. Todavia, não conseguem discernir quais instrumentos reiteram a imperatividade da masculinização, inscritos sobre as interpretações acerca dos elementos corporais e de corporeidade, e das noções sobre feminilidade, masculinidade, passividade, atividade e versatilidade sexuais.

Tanto para "Tired!" como para "Pantera Negra" é inexorável a correlação entre papéis sexuais e as performances de gênero. Para ambos, o exercício da passividade ou da versatilidade sexual (que tem, por um lado, o exercício da passividade) instigariam traços de feminilidade, demandando como resposta a discrição e a exacerbação da masculinização. Porém, os informantes não identificam as pressões exercidas pelas relações (ou crenças) com o bairro onde vivem, relações estas que, por conta do objetivo e das configurações metodológicas da pesquisa, não puderam ser observadas em sua 
profundidade, sendo pontuadas na metodologia como forma de observação a partir da própria dinâmica do objeto. Mas, ao que tudo indica, a relação online-offline tem função preponderante na compressão dos usuários ao exercício do que chamaremos aqui de "tripla aparência".

As três camadas de subjetivação da homossexualidade masculina funcionam da seguinte maneira: em uma primeira camada, a masculinidade heterossexual desenvolve dispositivos pelos quais forja ideologicamente ser a única forma de identificação do sujeito detentor de um órgão sexual (pênis) considerado masculino, justificando a existência da própria heterossexualidade; em uma segunda camada, o modelo de masculinização é imposto aos sujeitos homossexuais masculinos como uma moeda de troca em torno da cidadania nas práticas cotidianas, significando a necessidade de modelagem do corpo e da corporeidade; em sua última camada, decorrente da anterior, a homossexualidade masculina precisa perceber os traços de feminilidade e refreá-los por meio da discrição e da exacerbação dos traços da masculinização, forjando uma heterossexualidade aparente em práticas públicas.

Por último, e talvez o dado mais importante coletado, constatamos que a última camada de subjetivação é materializada de forma performativamente debilitada pelos "machões e discretos". Por conta dos papéis sexuais e pela ausência de uma regulação com plena eficácia, os usuários não conseguem controlar todos os traços de feminilidade, vacilando em determinados momentos. Ao reconhecer isso, projetam no parceiro-empotencial as demandas que não conseguem cumprir, que estão presentes na superfície textual dos perfis e nas categorias de identificação no Grindr. Portanto, menos um resultado individual de desejo sexual/amoroso, a inscrição da masculinização nos discursos de vários usuários do Grindr é efeito de uma sintaxe histórica e cultural que joga com os lugares que os sujeitos dissidentes podem ocupar.

\section{REFERÊNCIAS}

BOURDIEU, Pierre. A dominação masculina. Trad. Maria Helena Kühner. 11 ed. Rio de Janeiro: Berthand Brasil, 2012.

BUTLER, Judith. Sujeitos do sexo/gênero/desejo. Problemas de gênero: feminismo e subversão da identidade. Rio de Janeiro: Civilização Brasileira, 2003.

CHOULIARAKI, Lilie; FAIRCLOUGH, Norman. Discourse in late modernity: rethinking critical discourse analysis. Edinburgh: Edinburgh University Press, 1999.

CORRÊA, Júlia Antônia Maués; CRUZ, Marcos da Silva. Entre machos e discretos: discursos, identidades homoeróticas masculinas $\mathrm{e}(\mathrm{m})$ aplicativos de relacionamento. Heterotópica, Uberlândia, v.1, n2, p.108-135, 2019.

CRUZ, Marcos da Silva. Masculinidades e discrição em um aplicativo de relacionamento: discursos sobre identidades homossexuais masculinas. Revista Interdisciplinar em Estudos de Linguagem. v.2, n.2, 2020, p.1-19.

FAIRCLOUGH, Norman. Discurso e mudança social. Tradução: Izabel Magalhães. Brasília: Editora Universidade de Brasília, 2001. 
FAIRCLOUGH, Norman. Análise crítica do discurso como método em pesquisa social científica. Linha d'água, v.2, n.25, p.307-329, 2012. (Trad. Iran Ferreira de Melo).

FAIRCLOUGH, Norman. Análise crítica do discurso como raciocínio dialético: crítica, explanação e ação. Trad. Mycon Silva Aguiar. Policromias, ano 5, p.31-50, 2020.

FOUCAULT, Michel. A história da sexualidade: a vontade de saber. Trad. Maria Thereza da Costa Albuquerque e J. A. Guilhon Albuquerque. Rio de Janeiro: Edições Graal, 1988.

HALL, Stuart. A identidade em questão. In: Identidade cultural na pósmodernidade. Trad. Tomaz Tadeu da Silva e Guacira Lopes Louro. 11 ed. Rio de Janeiro: DP\&A, 2006. Cap. 1, p. 7-22.

LIVIA, Anna; HALL, Kira. "É uma menina!": a volta da performatividade à linguística. In: OSTERMANN, Ana Cristina; FONTANA, Beatriz (orgs.). Linguagem. Gênero. Sexualidade: clássicos traduzidos. São Paulo: Parábola Editorial, 2010.

LOURO, Guacira Lopes. Teoria queer: uma política pós-identitária para a educação, Estudos Feministas, v.9, n.2, p.541-553, 2001.

MIGNOLO, Walter. Desobediência epistêmica: a opção descolonial e o significado de identidade em política. Caderno de Letras da UFF, Dossiê: Literatura, língua e identidade, n. 34, p. 287-324, 2008.

MOITA-LOPES, Luiz Paulo. Lingüística Aplicada e vida contemporânea: problematização dos constructos que têm orientado a pesquisa. IN: Por uma

Linguística Indisciplinar. São Paulo: Parábola, 2006. Cap.3, p.85-107.

MOITA-LOPES, Luiz Paulo. Identidades Fragmentadas: a construção discursiva de raça, gênero e sexualidade em sala de aula. Campina, SP: Mercado de Letras, 2002.

MISKOLCI, Richard. Desejos digitais: uma análise sociológica da busca por parceiro on-line. Belo Horizonte, MG: Autêntica Editora, 2017.

PERLONGHER, Néstor. O negócio do michê: a prostituição viril em São Paulo. São Paulo: Editora Brasiliense, 1987.

PRECIADO, Beatriz. Manifesto Contrassexual: práticas subversivas de identidade. São Paulo: n-1 Edicões, 2014.

REIS, Ramon. Concurso Marquinha de Biquíni: visibilidades político-corporais entre jovens homossexuais em um bairro "periférico" de Belém. Bagoas, Natal, v.7, n.13, 2015, p.323-351.

SANTOS FILHO, Ismar Inácio dos. A construção discursiva de masculinidades bissexuais: um estudo em linguística queer. 2012. 248 f. Tese (Doutorado em Linguística) - Universidade Federal de Pernambuco, Recife, 2012.

SEDWICK, Eve Kosofsky. A epistemologia do armário. Cadernos Pagu, Campinas, São Paulo, v.28, n.1, p.19-54, jan./jun. 2007.

SOARES, Alexandre Sebastião Ferrari. A homossexualidade e a AIDS no imaginário de revistas semanais. Fragmentum, n.29, parte 1, p.13-20, 2011.

TREVISAN, João Silvério. Devassos no paraíso: a homossexualidade no Brasil, da colônia à atualidade. 4ed. Rio de Janeiro: Objetiva, 2018.

Artigo recebido em: abr. de 2020.

Aprovado e revisado em: out. de 2020.

Publicado em: dez. de 2020. 
Para citar este texto:

CORRÊA, Júlia Antônia Maués; CRUZ, Marcos da Silva. Masculinização da Homossexualidade Masculina no Grindr: discursos sobre masculinidade e discrição. Entremeios [Revista de Estudos do Discurso, ISSN 2179-3514, on-line, www.entremeios.inf.br], Seção Estudos, Programa de Pós-Graduação em Ciências da Linguagem (PPGCL), Universidade do Vale do Sapucaí (UNIVÁS), Pouso Alegre (MG), vol. 22, p. 32-46, jul. - dez. 2020.

DOI: http://dx.doi.org/10.20337/ISSN2179-3514revistaENTREMEIOSvol22pagina32a46 